\title{
Nucleocytoplasmic transport: the influenza virus NS1 protein regulates the transport of spliced NS2 mRNA and its precursor NS1 mRNA
}

\author{
Firelli V. Alonso-Caplen, ${ }^{1}$ Martin E. Nemeroff, Yun Qiu, and Robert M. Krug \\ Department of Molecular Biology and Biochemistry, Rutgers University, Center for Advanced Biotechnology and Medicine, \\ Piscataway, New Jersey 08855-1179 USA
}

Influenza virus unspliced NS1 mRNA, like retroviral pre-mRNAs, is efficiently exported from the nucleus and translated in the cytoplasm of infected cells. With human immunodeficiency virus (HIV), the transport of viral pre-mRNAs is facilitated by the viral Rev protein. We tested the possibility that the influenza virus NS1 protein, a nuclear protein that is encoded by unspliced NS1 mRNA, has the same function as the HIV Rev protein. Surprisingly, using transient transfection assays, we found that rather than facilitating the nucleocytoplasmic transport of unspliced NS1 mRNA, the NS1 protein inhibited the transport of NS2 mRNA, the spliced mRNA generated from NS1 mRNA. The efficient transport of NS2 mRNA from the nucleus to the cytoplasm occurred only when the synthesis of the NS1 protein was abrogated by amber mutations. The NS1 protein down-regulated the export of NS2 mRNA whether or not it was generated by splicing, indicating that the NS1 protein acted directly on transport. Actinomycin D chase experiments verified that the NS1 protein acted on the transport and not on the differential stability of NS2 mRNA in the nucleus as compared to the cytoplasm. In addition, the NS1 protein inhibited the transport of NS1 mRNA itself, which contains all of the sequences in NS2 mRNA, particularly when NS1 mRNA was released from the splicing machinery by mutating its 3'-splice site. Our results indicate that the NS1 protein-mediated inhibition of transport requires sequences in NS2 mRNA. The transport of the viral PB1 protein, nucleocapsid protein, hemagglutinin, membrane protein, and M2 mRNAs was not affected by the NS1 protein. When the NS2 mRNA sequence was covalently attached to the PB1 mRNA, the transport of the chimeric mRNA was inhibited by the NS1 protein. Our results identify a novel function of the influenza virus NS1 protein and demonstrate that post-transcriptional control of gene expression can also occur at the level of the nucleocytoplasmic transport of a mature, spliced mRNA.

[Key Words: Nucleocytoplasmic transport; mRNA; influenza virus; NS1 protein]

Received August 13, 1991; revised version accepted December 19, 1991.

The influenza virus-encoded nonstructural protein 1 (NS1 protein) accumulates in the nucleus and is not incorporated into virions. This protein was first identified in 1971 (Lazarowitz et al. 1971), but its function has not yet been determined. Data with temperature-sensitive virus mutants suggested that the NSl protein might be involved in the synthesis of virion RNA and/or in the switch to a late pattern of viral protein synthesis (Compans 1973; Wolstenholme et al. 1980; Koennecke et al. 1981; Shimizu et al. 1982). However, recent experiments have indicated that it is unlikely that the NS1 protein is involved in virion RNA synthesis. An in vitro system that synthesizes virion RNA was not affected by the removal of endogenous NS1 protein (Shapiro and Krug

${ }^{1}$ Present address: The Salk Institute, Swiftwater, Pennsylvania 18370 USA.
1988). In addition, the replication of a recombinant influenza virus genome segment did not require the NS1 protein (Huang et al. 1990).

As an alternative possibility, we hypothesized that the NS1 protein has a function similar to that of the nuclear Rev protein of human immunodeficiency virus type 1 (HIV-1) (Hadzopoulou-Cladaras et al. 1989; Malim et al. $1989 \mathrm{~b})$. With both influenza virus and HIV-1, splicing is regulated such that only a portion rather than all of the viral pre-mRNA is spliced, and the unspliced premRNA, which also encodes a protein(s), is transported from the nucleus to the cytoplasm (Lamb and Lai 1980; Lamb et al. 1980, 1981; Chang and Sharp 1989; Malim et al. 1989b). With HIV-1, the viral Rev protein interacts with a sequence in unspliced viral pre-mRNA and mediates the transport of this unspliced pre-mRNA from the nucleus (Hadzopoulou-Cladaras et al. 1989; Malim et 
al. $1989 \mathrm{~b})$. In the absence of the Rev protein, the HIV pre-mRNA accumulates in the nucleus. The Rex protein of human T-cell leukemia virus (HTLV) has the same function (Hanly et al. 1989). It can be postulated that the influenza virus NS1 protein, a nuclear protein (Briedis et al. 1981; Greenspan et al. 1988), serves the same role.

One of the influenza viral mRNAs that undergoes splicing is NS1 mRNA, the mRNA that encodes the NS1 protein. A portion of this mRNA is spliced to form NS2 mRNA, which encodes another non-structural protein, the NS2 protein (Inglis et al. 1979; Lamb and Choppin 1979). We inserted the NS1 gene into a transient transfection vector and determined whether the NS1 protein mediated the transport of unspliced NSI mRNA from the nucleus to the cytoplasm. Surprisingly, we found that rather than facilitating the nucleocytoplasmic transport of NS1 mRNA, the NS1 protein inhibited the transport of spliced NS2 mRNA. Our results indicate that the NS1 protein most likely regulates the nuclear export of NS2 mRNA in a sequence-specific manner. These results identify a novel function of the influenza virus NS1 protein and demonstrate that post-transcriptional control of gene expression can occur at the level of the nucleocytoplasmic transport of a mature, spliced mRNA. In addition, the NSI protein inhibited the nucleocytoplasmic transport of its own mRNA-NS1 mRNA-which contains all of the sequences in NS2 mRNA. The inhibition of NSI mRNA transport was most evident when it was released from the splicing machinery by mutating its 3 '-splice site.

\section{Results}

The effect of the NS1 and NS2 proteins on the nuclear/cytoplasmic distribution of NS1 and NS2 mRNAs

Transient transfections were carried out to determine the role of the NS1 and NS2 proteins in the nuclear export of the NS1 and NS2 mRNAs. The NS1 gene was inserted into a vector $(\mathrm{pBC12})$ under the control of the cytomegalovirus (CMV) major immediate early promoter. The NSl gene was either wild type or contained amber mutations in the NS1 and/or NS2 reading frames (Fig. 1A). COS cells were transfected with each of these plasmids, and the transfected cells were fractionated into nuclei and cytoplasm. Cell-equivalent amounts of nuclear and cytoplasmic RNA, namely 0.5 and $5 \mu \mathrm{g}$, respectively, were used for S1 analysis (Fig. 1).
In cells transfected with the wild-type NS1 gene (NS1), very little $(8 \%)$ of the unspliced NS1 mRNA was found in the cytoplasm (Fig. 1C, lanes 1,2), suggesting that the NS1 protein did not facilitate the transport of unspliced NS1 mRNA from the nucleus. Eliminating the synthesis of the NSl protein by one (NSla) or two (NSldm) amber mutations actually increased the percentage of the NS1 mRNA in the cytoplasm by about threefold (lanes 3-6). As will be documented below, this increase can be attributed to the absence of the NS1 protein.

The effects of the NS1 protein on the nuclear/cytoplasmic distribution of spliced NS2 mRNA were even more surprising. In cells synthesizing the NSI protein (Fig. 1C, lanes 1,2$)$, very little $(10 \%)$ of spliced NS2 mRNA was found in the cytoplasm. Elimination of the synthesis of the NS1 protein by amber mutations (lanes 3-6) increased the percentage of the NS2 mRNA in the cytoplasm by five- to sixfold. The amber mutation in the NS2 reading frame (NS2a) had essentially no effect on the percentage of the NS2 mRNA in the cytoplasm (lanes $7,8)$. With the amber mutations in both the NS1 and NS2 reading frames (NSam3), the percentage of the NS2 mRNA in the cytoplasm (lanes 9,10) was increased to approximately the same extent as with amber mutations in the NS1 reading frame alone (lanes 3-6). Surprisingly, these results suggested that the NSI protein inhibited the transport of spliced NS2 mRNA from the nucleus.

If this were the case, amber mutations in the NSl reading frame should result in a stimulation in the synthesis of the NS2 protein. To test this possibility, COS cells at $72 \mathrm{hr}$ after transfection were labeled with $\left.\right|^{35}$ S|methionine for $6 \mathrm{hr}$, and equal aliquots were immunoprecipitated with antiserum against either the NS1 or NS2 protein (Fig. 2). In cells transfected with the wild-type NS1 gene (lanes 2,8), both the NS1 and NS2 proteins were synthesized, indicating that the small percentage of the NS 1 and NS2 mRNAs that was detected in the cytoplasmic fraction (Fig. 1) was actually in the cytoplasm and active in protein synthesis. When NS1 protein synthesis was eliminated by one or two amber mutations (Fig. 2, lanes $9,10 \mid$, the synthesis of the NS2 protein was stimulated five- to sixfold, the same stimulation that was observed in the percentage of NS2 mRNA that was cytoplasmic (Fig. 1). This supports the possibility that the NS1 protein inhibited the transport of spliced NS2 mRNA.

The results shown in Figures 1 and 2 were surprising and exactly opposite to what was postulated. Accordingly, we sought confirmation by other experiments. The most straightforward interpretation of the results

Figure 1. The NS1 protein shifted spliced NS2 mRNA into the nucleus. (A) Mutations were introduced using oligonucleotidedirected mutagenesis. For NS1 protein amber mutants (NSla and NS1dm), mutations were introduced into the intron region so that the NS2 amino acid sequence was not affected. With the NS2 protein amber mutant (NS2a), the introduced mutation did not alter the amino acid sequence of the NSI protein, because the two proteins are read off different reading frames. The double amber mutant (NSam3) contained the amber mutations introduced into both the NS1 and NS2 reading frames. $(C)$ COS cells were transfected for 48 $\mathrm{hr}$ with the plasmids encoding the indicated NS1 mRNAs. Cells were then fractionated into nuclei and cytoplasm, and the nuclear and cytoplasmic RNAs were analyzed by $\mathrm{S} 1$ nuclease assays using the probe depicted in $B$. The preparation of this probe is described in Materials and methods. After S1 nuclease digestion, the protected fragments were resolved on a $5 \%$ denaturing polyacrylamide gel. The relative amounts of the NS1 and NS2 mRNAs were determined by densitometry of the X-ray film of the gel. The percentage of the NS1 and NS2 mRNAs that were in the cytoplasm is indicated under the appropriate lanes. 
Regulated nuclear export of RNA

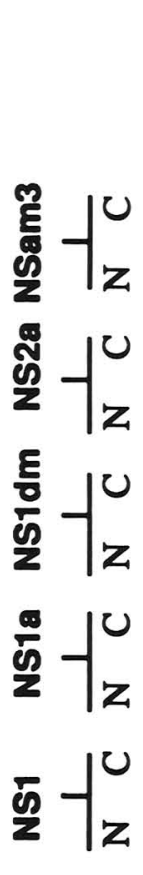

8
8
4
0

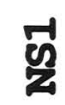

羿

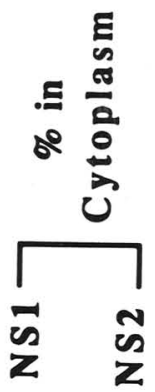

है
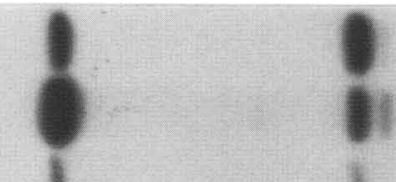

잉

ล้ ๕̊

の

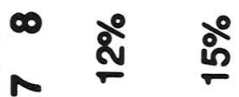

1 8 \&

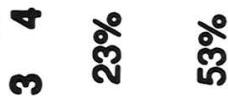

- \&̊ 웅

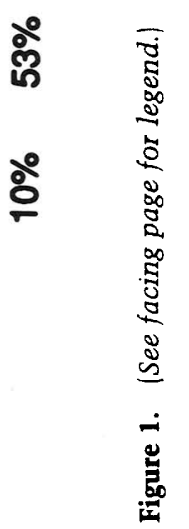
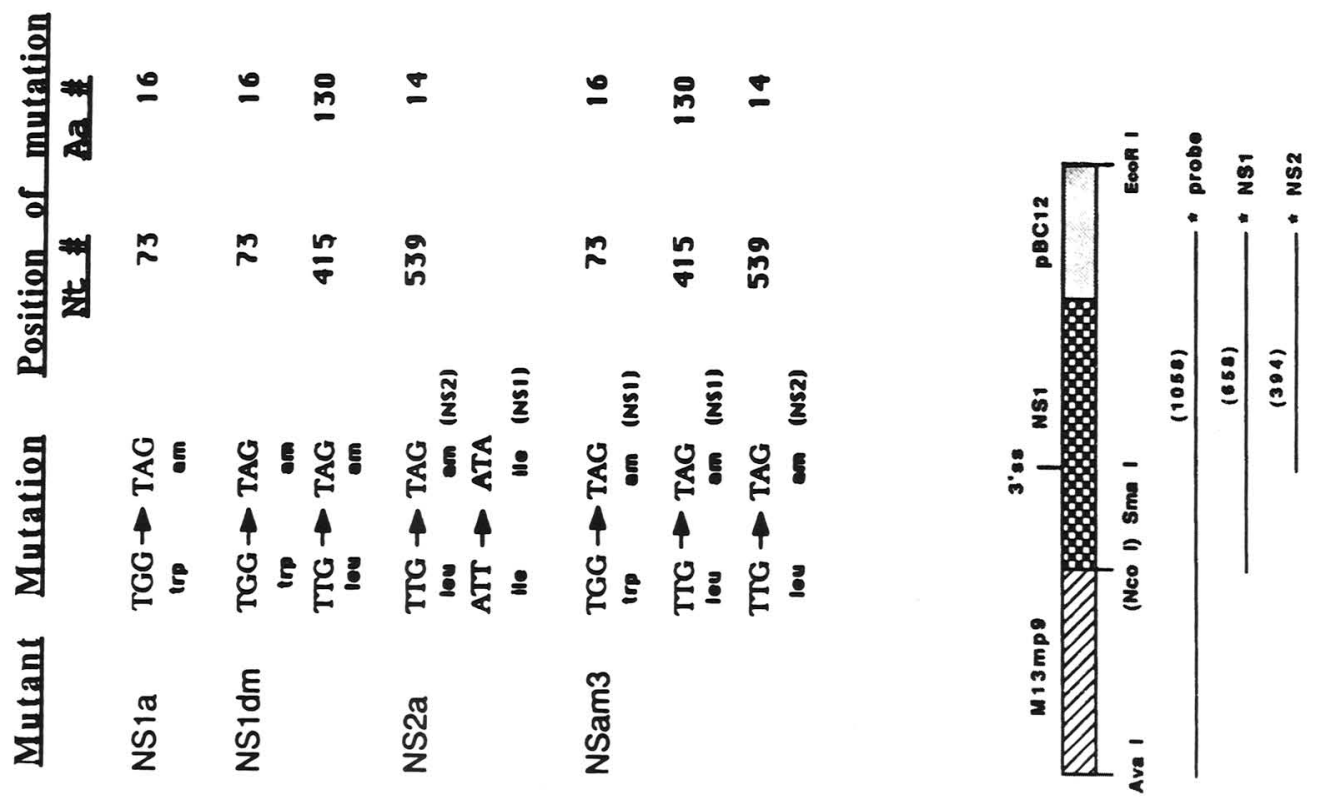
Figure 2. Abrogation of NS1 protein synthesis by thesis of the NS2 protein. COS cells were transfected with the plasmids encoding the indicated NS1 mRNAs. At $72 \mathrm{hr}$ post-transfection, the cells were labeled with $\left[{ }^{35} \mathrm{~S}\right]$ methionine, and aliquots of the cell lysates were immunoprecipitated with antiNS1 (lanes 2-6) or anti-NS2 (lanes 8-12) antibodies, followed by gel electrophoresis. The relative amounts of the NS2 protein in lanes 8-10 were determined by densitometry of the X-ray film of the gel. Lysate from cells infected for $4 \mathrm{hr}$ with influenza virus $\mathrm{A} / \mathrm{Udorn} / 72$ was used as markers for the NS1 and NS2 proteins (lanes 1 and 7, respectively). The aliquot used in lane 1 was one-tenth that used in lane 7. amber mutations led to significantly enhanced syn-
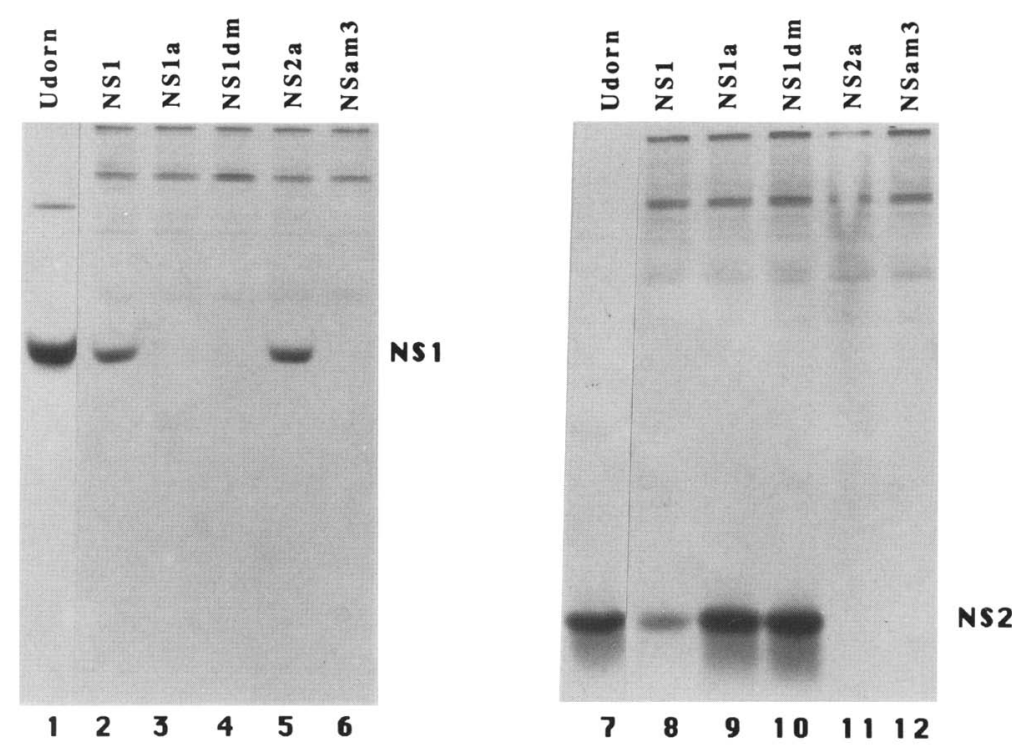

was that the NS1 protein directly inhibited the nucleocytoplasmic transport of NS2 (and possibly NS1) mRNA. However, two other interpretations were possible. First, the NS1 protein might be acting via splicing, for example, by inhibiting the dissociation of spliced NS2 mRNA from spliceosomes, a step that has recently been shown to require the action of an ATP-requiring protein (Company et al. 1990). Second, the NS1 protein might be differentially stabilizing the NS2 mRNA in the nucleus and/or destabilizing the NS2 mRNA in the cytoplasm. We tested these two other possibilities experimentally.

The effect of the NS1 protein on the nuclear/cytoplasmic distribution of NS2 mRNA was independent of splicing

If the NS1 protein directly inhibited the transport of NS2 mRNA, then the NS1 protein-mediated nuclear retention of NS1 mRNA should not be dependent on NS2 mRNA being generated by splicing. For these experiments, NS2 mRNA was expressed without splicing by transfecting the cells with a plasmid containing NS2 cDNA. The NS1 protein was provided in trans by a second plasmid encoding an NS1 mRNA in which the $3^{\prime}$ splice site AG was mutated to CG and the polypyrimi- dine tract was disrupted by mutating a $\mathrm{T}$ to an A (NS3ss; Fig. 3a). These mutations did not cause a change in the amino acid sequence of the NS1 protein. As shown previously (Alonso-Caplen and Krug 1991), this mutated NS1 mRNA was not spliced to form NS2 mRNA, and at least some of this NS1 mRNA was exported from the nucleus and translated (also see below). The control plasmid [NS3ss $(\mathrm{dm}) \mid$ not only contained these 3 '-splice site mutations but also two amber mutations in the NS1 protein reading frame, so that although NS1 mRNA was made, no NSI protein was synthesized. Transfections were carried out in 293 cells. Because the plasmids do not replicate in these cells, it was possible to control the relative amounts of the putative target (NS2 mRNA) and effector molecules (NS1 protein). When the control plasmid and the NS2 cDNA plasmid (at a $2: 1$ ratio) were cotransfected into 293 cells, the majority $(72 \%)$ of the NS2 mRNA was in the cytoplasm (Fig. 3b, lanes 1,2). In contrast, when the NS3ss and NS2 cDNA plasmids (at the same $2: 1$ ratiol were cotransfected into 293 cells, only $10 \%$ of the NS2 mRNA was in the cytoplasm (lanes $3,4)$. The shift in the nuclear/cytoplasmic ratio of the NS2 mRNA caused by the NS1 protein was $\sim 23$-fold. These results suggested that the NS1 protein inhibited the transport of NS2 mRNA whether or not it was generated by splicing.

Figure 3. The NS1 protein-mediated shift of NS2 mRNA into the nucleus was independent of splicing. $(a)$ As a source of the NS1 protein supplied in trans, the NS3ss construct was used. In this construct, mutations were introduced that disrupted the polypyrimidine tract and altered the $3^{\prime}$-splice site AG $\rightarrow$ CG, without affecting the NS1 reading frame. As a control, the NS3ss(dm) mutant was constructed, which not only contained the $3^{\prime}$-splice site mutations but also two amber mutations in the NS1 protein reading frame. (b) 293 cells were cotransfected with either the NS3ss(dm) $1-\mathrm{NS} 1$ protein) and the NS2 cDNA plasmids at a ratio of $2: 1$ (lanes 1,2) or the NS3ss (+NS1 protein) and the NS2 cDNA plasmids at a ratio of $2: 1$ (lanes 3,4). All cells were also transfected with the plasmid containing the $\beta$-globin minigene. At $40 \mathrm{hr}$ post-transfection, the cells were fractionated into nuclei and cytoplasm. The nuclear and cytoplasmic RNA was extracted and subjected to S1 analysis, using the NS-specific probe and $\beta$-globin probe depicted in $c$ (see Materials and methods|. The NS-specific probe detected both the NS2 and NS1 mRNAs. The percentage of the NS1 and NS2 mRNAs and unspliced $\beta$-globin $(\mathrm{uGL})$ mRNA that were in the cytoplasm is indicated under the appropriate lanes. It should be noted that the unspliced $\beta$-globin $(\mathrm{uGL} / \mathrm{mRNA}$ was predominantly in the nucleus both in the absence and presence of the NS1 protein. Spliced $\beta$-globin mRNA was predominantly in the cytoplasm (not shown here). 

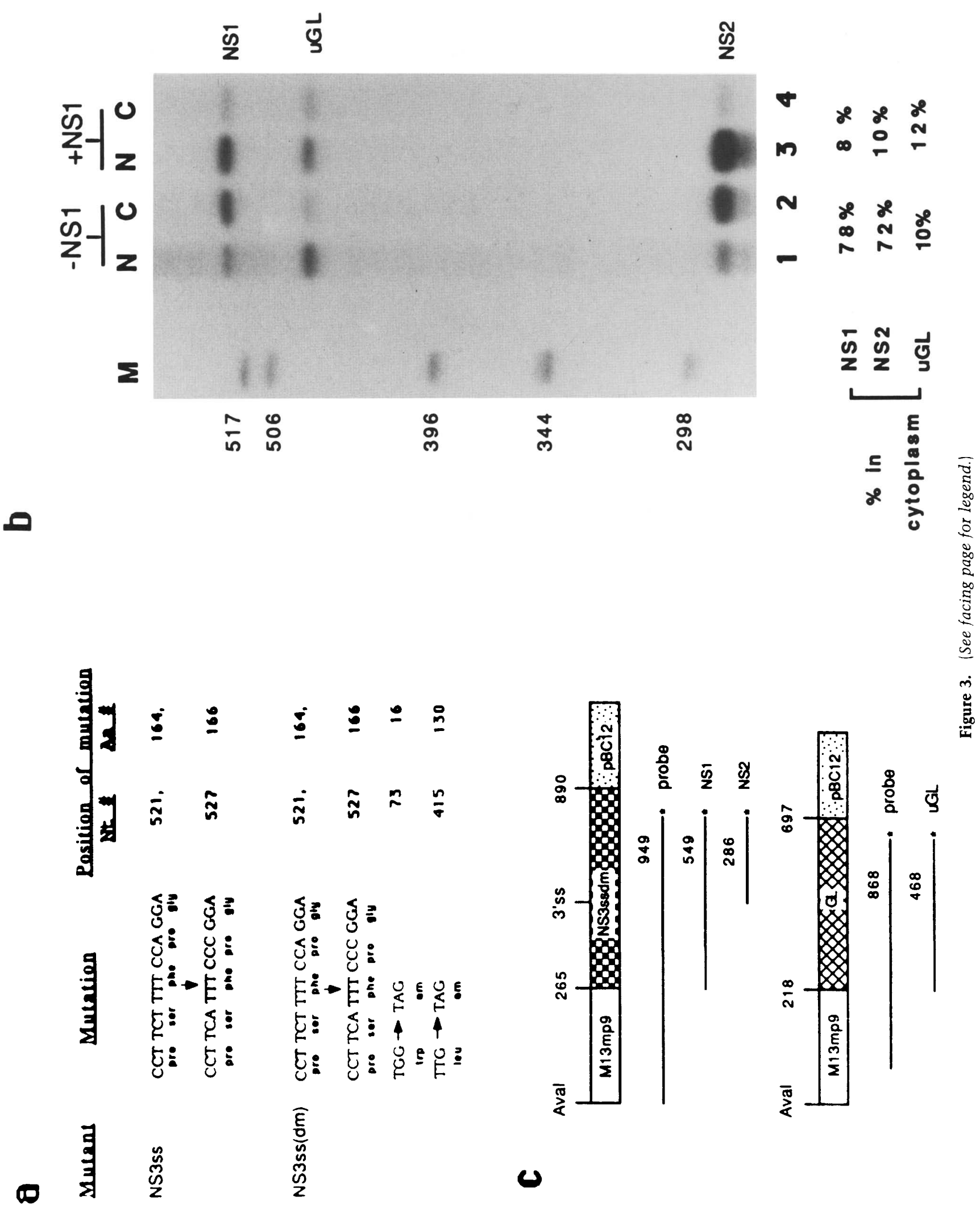
As shown previously (Alonso-Caplen and Krug 1991), mutation of the 3'-splice site of unspliced NS1 mRNA diverts this mRNA from spliceosomes. The transport of this mutated NS1 mRNA, like that of spliced NS2 mRNA, was regulated by the NS1 protein. Only a small percentage $(8 \%)$ of the NS1 mRNA encoded by the NS3ss plasmid was found in the cytoplasm (Fig. 3b, lanes $1,2)$, whereas the majority $(78 \%)$ of the NS1 mRNA encoded by the NS3ss(dm) plasmid was in the cytoplasm (Fig. 3b, lanes 3,4). The shift in the nuclear/cytoplasmic ratio of the NS1 mRNA caused by the NS1 protein was $\sim 40$-fold. Hence, mutation of its 3'-splice site rendered NS1 mRNA more susceptible to regulation by the NSI protein, as the effect of the NSI protein on the nuclear/ cytoplasmic distribution of wild-type spliceable NS1 mRNA was much smaller (see Discussion; Fig. 1).

The NS1 protein did not differentially affect the stability of NS2 mRNAs in the nucleus as compared with the cytoplasm

To exclude the possibility that the NS1 protein either stabilized the NS2 mRNA in the nucleus or destabilized the NS2 mRNA in the cytoplasm, we carried out an actinomycin D chase experiment. 293 cells were cotransfected (at a $2: 1$ ratio) either with the NS3ss $(\mathrm{dm})(-\mathrm{NS} 1$ protein| and NS2 cDNA plasmids or with the NS3ss (+ NS 1 protein) and NS2 cDNA plasmids. At $40 \mathrm{hr}$ after transfection, actinomycin $\mathrm{D}(5 \mathrm{mg} / \mathrm{ml})$ was added. The amount of NS2 mRNA in the nucleus and cytoplasm was determined at the time of actinomycin $\mathrm{D}$ addition and 1 and $4 \mathrm{hr}$ later (Fig. 4). Both in the absence and the presence of the NS1 protein, cytoplasmic NS2 mRNA was less stable than nuclear NS2 mRNA during the course of the actinomycin D treatment. The stability of the NS2 mRNA was slightly higher in the presence of the NS1 protein, but the magnitude of this effect was the same in the nucleus and cytoplasm. Thus, the NS1 protein did not differentially destabilize the NS2 mRNA in the cytoplasm or differentially stabilize the NS2 mRNA in the nucleus. Similar results were obtained with NS1 mRNA containing the 3 -splice site mutation, and the same results were also obtained in COS cell transfections (data not shown). Consequently, it can be concluded that the NS1 protein was regulating the nucleocytoplasmic transport of NS2 and NS1 mRNAs.

\section{The NS1 protein-mediated inhibition of transport is sequence-specific}

We determined whether the NSl protein affected the nucleocytoplasmic transport of other influenza viral mRNAs. First, we examined the effect of the NS1 protein on the transport of the other influenza virus-spliced mRNA-M2 mRNA encoding an integral membrane protein. This mRNA is generated from Ml mRNA (encoding the membrane protein) utilizing one of two alternative $5^{\prime}$-splice sites (Inglis and Brown 1981; Lamb et al. 1981). When the other $5^{\prime}$-splice site is utilized, another mRNA, mRNA 3 , which has only a 9-amino-acid open reading frame, is generated. The $\mathrm{mRNA}_{3} 5^{\prime}$-splice site

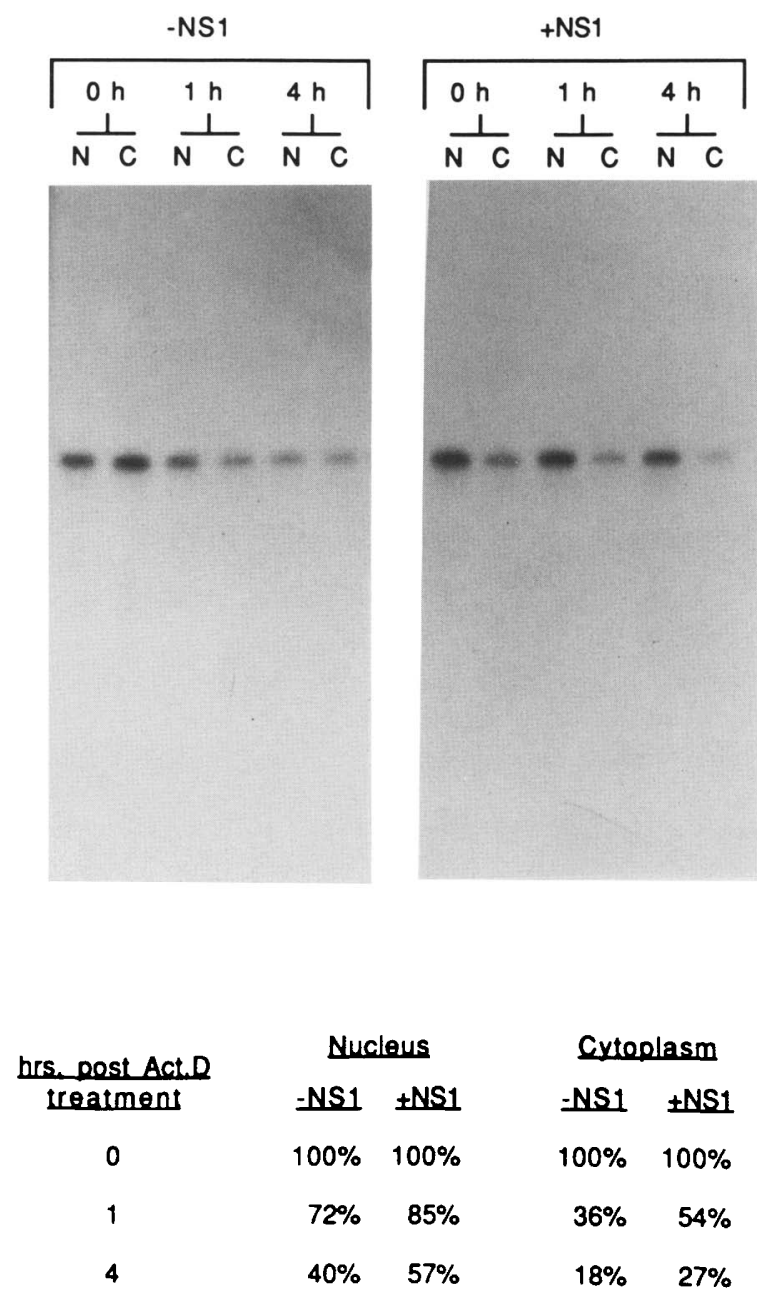

NS2

Figure 4. The NSl protein did not differentially affect the stability of NS2 mRNA in the nucleus as compared to the cytoplasm. 293 cells were cotransfected with either the NS3ss(dm) (-NS1 protein) and NS2 cDNA plasmids at a $2: 1$ ratio or the NS3ss (+ NS1 protein) and NS2 cDNA plasmids at a $2: 1$ ratio. At $40 \mathrm{hr}$ post-transfection, cells were either harvested without actinomycin D treatment $(0 \mathrm{hr})$ or treated for 1 or $4 \mathrm{hr}$ with 5 $\mu \mathrm{g} / \mathrm{ml}$ of actinomycin D. Cells were then fractionated into nuclei and cytoplasm. The nuclear and cytoplasmic RNAs were extracted and subjected to $S 1$ analysis, using the probes shown in Fig. 1b. Equal amounts of RNA $15 \mu \mathrm{g}$ of cytoplasmic RNA and $0.5 \mu \mathrm{g}$ of nuclear RNA) were used from the different cell samples. $(b)$ The amount of NS2 mRNA in the nucleus and cytoplasm of each sample was determined by densitometry. The relative percentages of NS2 mRNA in the nucleus and cytoplasm at the indicated time points after actinomycin $D$ treatment are presented in the table below, considering the $0 \mathrm{hr}$ value as $100 \%$.

fits the consensus sequence much better than the M2 mRNA 5'-splice site (Fig. 5a) and, as documented previously (Lamb and Lai 1982), only the $\mathrm{mRNA}_{3} 5^{\prime}$-splice site was utilized when plasmids containing the Ml sequence were transfected into cells (data not shown). By mutating the $\mathrm{mRNA}_{3} 5^{\prime}$-splice site in the $\mathrm{M} 1$ sequence from GT to CT, M2 mRNA was synthesized in COS 
cells (Fig. 5b). The identity of the RNA band labeled M2 mRNA was verified by sequence analysis of the region around the splice junction, and both the M1 and M2 proteins were synthesized (data not shown). In both the absence of the NS1 protein [cotransfection with NS3ss $(\mathrm{dm})$ plasmid] and the presence of the NS1 protein (cotransfection with NS3ss plasmid), the majority $(80 \%$ ) of M2 mRNA was in the cytoplasm. This indicates that the NSl protein had no effect on the transport of spliced M2 mRNA. Similarly, the transport of spliced mRNA $_{3}$ was not affected (data not shown). It should also be noted that unspliced $M 1$ mRNA was largely $(85-90 \%)$ retained in the nucleus both in the absence and presence of the NS1 protein.

The effect of the NS1 protein on the nuclear export of other viral mRNAs was also examined. COS cells were transfected with either the PBI (polymerase basic protein 1), NP (nucleocapsid protein), or HA (hemagglutinin) gene in the presence of NS1 protein (supplied in trans by NS3ss plasmid) or its absence [cotransfection with control NS3ss (dm) plasmid]. As shown in Figure 5c, the NS1 protein clearly did not affect the nucleocytoplasmic transport of PBl, NP, or HA mRNA. These results obtained from cell fractionation studies were corroborated by translation assays (data not shown).

To verify that the NS1 protein recognized sequences in NS2 mRNA, we constructed a PB1-NS2 chimera and determined whether the transport of this chimeric mRNA was inhibited by the NS1 protein. In this chimeric mRNA, the NS2 mRNA sequence 1418 nucleotides) was flanked at its $5^{\prime}$ and $3^{\prime}$ ends by 2021 and 320 nucleotides of PBl sequences, respectively (Fig. 6b). Transfections were carried out in 293 cells (Fig. 6a). In these cells, PB1 mRNA was predominantly $(72 \%)$ in the cytoplasm, even in the presence of the NS1 protein. The PB1-NS2 chimeric mRNA was also predominantly in the cytoplasm $(78 \%)$ but only in the absence of the NS1 protein. As increasing amounts of the NS1 protein were provided by a cotransfected NS3ss plasmid, the PB1-NS2 chimeric mRNA was shifted to the nucleus. When the ratio of the NS3ss/PB1-NS2 chimera plasmids was 1.5, the target PB1-NS2 chimeric mRNA was distributed equally between the nucleus and cytoplasm. With a further increase in the ratio of the two plasmids to 3.0, only a minority $(13 \%)$ of the target PB1-NS2 chimeric mRNA was in the cytoplasm. The shift in the nuclear/cytoplasmic ratio of the chimeric RNA caused by the NS1 protein was $\sim 24$-fold. Thus, the NSl protein-mediated inhibition of transport requires sequences in NS2 mRNA.

\section{Discussion}

We set out to determine whether the influenza virus NS1 protein functioned like the HIV Rev protein, namely that the NS1 protein facilitated the nucleocytoplasmic transport of an unspliced pre-mRNA-NS1 mRNA. Instead, to our surprise, we discovered that the NS1 protein regulated the nucleocytoplasmic transport of mRNA in a way that was opposite to that of the wildtype Rev and HTLV Rex proteins. The influenza virus
NS1 protein inhibited the nuclear export of specific $\mathrm{mR}$ NAs. It inhibited the transport of a spliced mRNA-the viral NS2 mRNA - and also the transport of unspliced NS1 mRNA - the precursor to NS2 mRNA. The inhibition of NS1 mRNA transport was most evident when it was released from its association with the splicing machinery by mutating its 3 '-splice site. The shift in the nuclear/cytoplasmic ratio of NS2 and NS1 mRNA caused by the NS1 protein was large-20- to 40 -fold in most experiments. Consequently, the NS1 protein may be comparable to the trans-dominant mutants of the Rev and Rex proteins, which apparently inhibit, rather than facilitate, nuclear export of their target mRNAs (Malim et al. 1989a; Bohnlein et al. 1991).

Like the Rev and Rex proteins, the influenza virus NS1 protein appears to regulate the nucleocytoplasmic transport of mRNA in a sequence-specific manner. Of the seven influenza viral mRNAs that were tested, only the transport of the NS1 and NS2 mRNAs, which share common sequences, was inhibited by the NS1 protein. In its RNA target, the Rev and Rex proteins each recognize an RNA sequence (responsive region, or RE) that forms a highly stable stem-loop structure (Heaphy et al. 1990; Kim et al. 1991), and the Rev protein has been shown to bind to its cognate RNA sequence (Daly et al. 1989; Zapp and Green 1989). Our results indicate that the NS1 protein-mediated inhibition of transport most likely requires sequences that are common to the NS1 and NS2 mRNAs. By analogy with the Rev protein, it is reasonable to expect that the NSI protein will bind to its cognate RNA sequence. The NS1 protein has been shown to bind to RNA (Yoshida et al. 1981; Skorko et al. 1991). Although these earlier studies did not report specificity in the binding of the NSl protein, we have found that the NS1 protein specifically binds to NS2 mRNA and have begun to define the specific binding site (Y. Qiu, M.E. Nemeroff, and R.M. Krug, unpubl.). Once this specific binding site is defined, it should be possible to determine whether the NSl protein will bind to, and inhibit the nucleocytoplasmic transport of, other mRNAs in addition to the viral NS1 and NS2 mRNAs.

Our evidence indicates that the NS1 protein acted directly on the nucleocytoplasmic transport of NS2 mRNA. The NS1 protein caused the nuclear retention of NS2 mRNA whether or not it was generated by splicing, indicating that the NS1 protein was not acting by affecting the splicing machinery. In addition, we carried out actinomycin D chase experiments to determine whether the NS1 protein differentially affected the stability of NS2 mRNA in the nucleus as compared with the cytoplasm. No such effect was found, indicating that the observed NS1 protein-mediated change in the nuclear/cytoplasmic ratio of the NS2 mRNA was the result of a block in the transport of NS2 mRNA caused by the NS1 protein.

The control of eukaryotic gene expression has been shown to occur at many levels: transcription, splicing, polyadenylation, and even nucleocytoplasmic transport of unspliced pre-mRNAs (Rev and Rex function). Here, we show that the control of gene expression can also 
occur at the level of the nucleocytoplasmic transport of a mature, spliced mRNA. A specific protein, the NS1 protein, regulates the nucleocytoplasmic transport of a specific mature, spliced mRNA - the NS2 mRNA-and, hence, regulates the amount of synthesis of the protein encoded by this mRNA. It will be important to determine whether this type of post-transcriptional regulation occurs in other systems.

\section{a}

Consensus 5' Splice Site

MI wildtype 5 ' Splice Sites

mRNA3 5' SS Mutont

$$
{ }_{A}^{C} \downarrow_{G T}^{A}{ }_{G} \text { AGT }
$$$$
{ }_{A}^{C} \downarrow_{G T}^{A} \text { AGT }
$$

MRNA3 5'SS

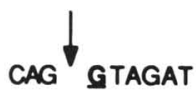

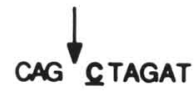

M25'SS

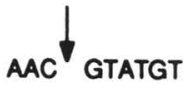<smiles></smiles>

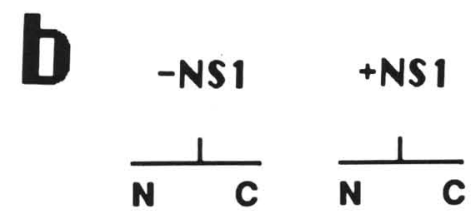

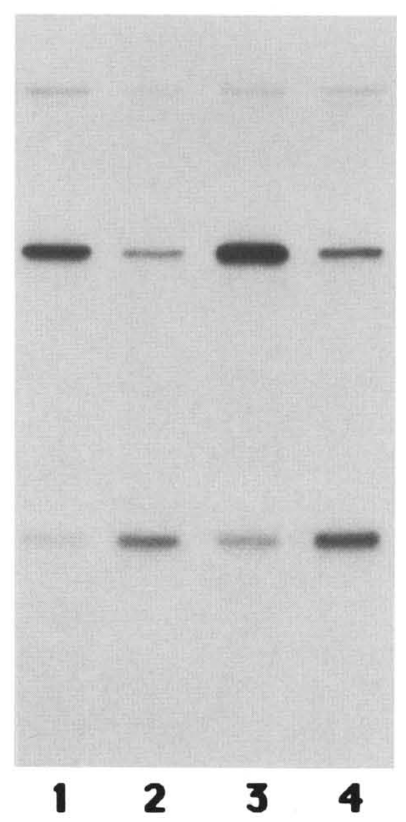

probe

M1

Figure 5. (See facing page for legend.)
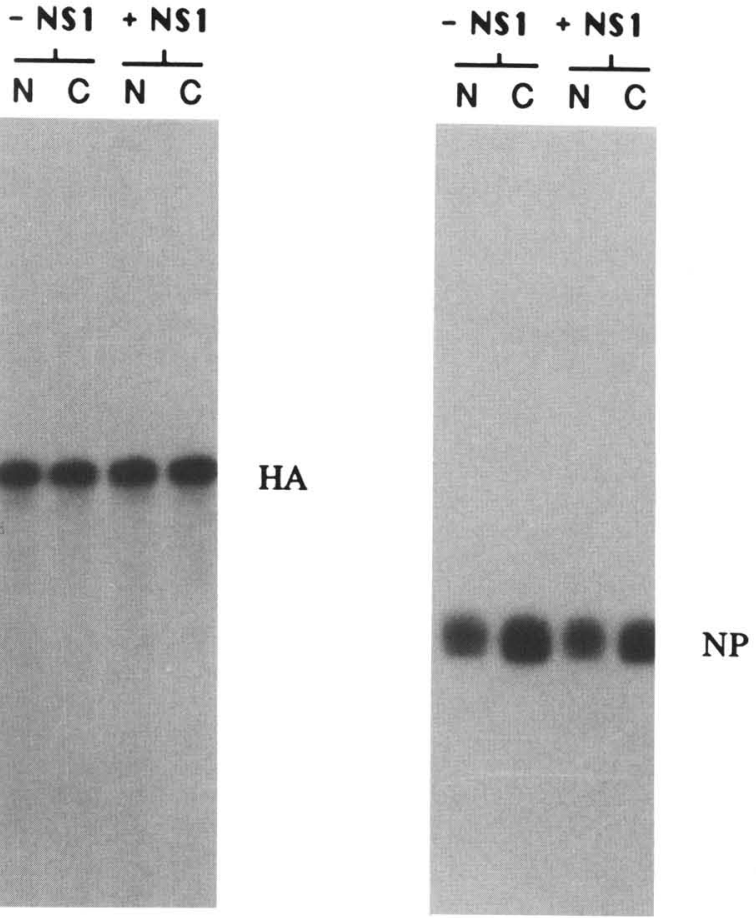

HA

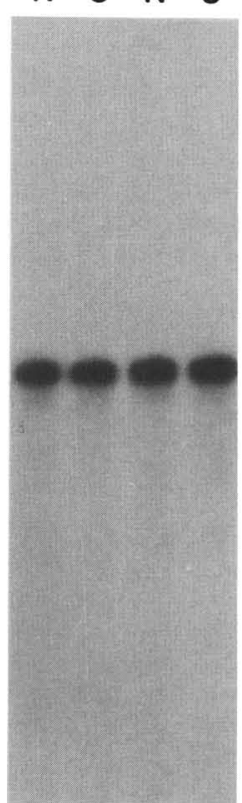

1631

517

506

396

344 
We predict that the NS1 protein via binding to its cognate sequence in NS2 mRNA will inhibit the transport of NS2 mRNA not only in transfected cells but also in influenza virus-infected cells. As a consequence, the amount of the NS2 protein in influenza virus-infected cells would be controlled at several levels (Fig. 7). First, the amount of NS2 mRNA that is generated by splicing would be suppressed. This would be accomplished both by the suppression of the rate of splicing of NS1 mRNA via cis-acting sequences in NS1 mRNA itself (Plotch and Krug 1986; Agris et al. 1989; Nemeroff et al. 1992) and by the enhanced nuclear export of unspliced NS1 mRNA. In addition, the NSl protein encoded by unspliced NS1 mRNA would down-regulate the nucleocytoplasmic transport of NS2 mRNA. This down-regulation may be necessary because, as discussed below, the transport of all viral mRNAs may be rapid in influenza virus-infected cells. Consequently, the genetic information in the influenza virus NS gene would be directed toward the regulated production of a low amount of the NS2 protein, one of the two proteins encoded in this gene. This regulation is entirely post-transcriptional, at the level of splicing and nuclear export of mRNA. There may be very little, if any, transcriptional control during influenza virus infection. At early times of infection, the NS1 and NP proteins are selectively synthesized (Hay et al. 1977; Smith and Hay 1982; Shapiro et al. 1987), but this is the result of the selective synthesis of specific genomic RNAs rather than the regulation of the amount of synthesis of mRNAs transcribed from these genomic RNAs. It is tempting to speculate that post-transcriptional controls of influenza viral gene expression evolved because, unlike DNA genomes, this viral RNA genome lacks upstream promoter-enhancer sequences that can be regulated by trans-acting factors. There is a common sequence of 12 nucleotides at the $3^{\prime}$-terminus of each of the eight genomic RNAs of influenza A virus (Skehel and Hay 1978; Desselberger et al. 1980; Robertson 1981), and as a consequence, selective and regulated transcription of a given genomic RNA segment may not be possible.

Why would it be necessary for influenza virus to regulate the synthesis of the NS2 protein so closely? This is difficult to answer because the function of the NS2 protein is not known. A recent paper reported the intriguing result that mutations in the NS2 reading frame were associated with the generation of defective-interfering RNAs derived from at least one of the three viral poly- merase genes (Odagiri and Tobita 1990). This might mean that the NS2 protein is involved in some aspect of viral RNA replication and that changes in the NS2 protein can lead to aberrant RNA synthesis. Perhaps the level of the NS2 protein must be closely controlled so that there is enough for efficient viral RNA replication but not an excess that could lead to aberrant RNA synthesis and the production of defective-interfering RNAs.

Does the NS1 protein also down-regulate the transport of its own mRNA in influenza virus-infected cells? In transfected cells, wild-type NS1 mRNA was inefficiently transported from the nucleus. Even though there was some increase in transport when the synthesis of the NSl protein was eliminated, the majority of the NSl mRNA remained in the nucleus, presumably because it was associated with spliceosomes. In contrast, NS1 mRNA containing a mutated 3 '-splice site was efficiently transported in the absence of the NS1 protein, presumably because it was not associated with spliceosomes, and the transport of this mutated NSI mRNA was effectively inhibited by the NS1 protein. A key question, then, is whether most of the nuclear NS1 mRNA in influenza virus-infected cells is on spliceosomes. If, as discussed below, most of the nuclear NS1 mRNA in infected cells is in the process of being rapidly transported rather than being associated with spliceosomes, then the transport of these NSI mRNA molecules would be expected to be regulated by the NSl protein.

The most definitive way to determine how the NSl protein regulates the transport of the NS2 and NS1 mRNAs in influenza virus-infected cells is to introduce into virus a NS gene that encodes a mutated loss-of-function NS1 protein. The technology for introducing specific mutations into the influenza virus genome has recently been developed (Luytjes et al. 1989). It is reasonable to hypothesize that the NSI protein has the same types of functional domains as the Rev protein: one that interacts with the target sequence, or RE, on the mRNA; and one that likely interacts with the nuclear export machinery (Malim et al. 1989a). Mutations in the latter domain of the Rev protein yield the trans-dominant Rev mutants. We are currently characterizing a series of mutant NSl proteins to identify the functional domains in the NSl protein. The appropriate mutant NS genes will then be introduced into virus.

Neither the NS1 protein nor the NS2 protein facilitated the nucleocytoplasmic transport of unspliced NSl mRNA, and the NS1 protein did not facilitate the trans-

Figure 5. The NS1 protein did not affect the nuclear export of other influenza viral mRNAs, including the viral spliced mRNA, M2 mRNA, and the PBl, HA, and NP mRNAs. (a) Transfection with the Ml gene produced only spliced mRNA and not M2 mRNA. To activate splicing at the M2 5'-splice site, the mRNA $5^{\prime}$ splice site was mutated, from GT to CT (mRNA $5_{3}^{\prime}$ 'ss mutant). (b) Cos cells were transfected with the plasmid containing the mutated RRNA $_{3} 5^{\prime}$ ss in the presence (cotransfection with NS3ss plasmid) or absence [cotransfection with NS3ss $(\mathrm{dm})$ plasmid] of the NS1 protein. At $48 \mathrm{hr}$ post-transfection, cells were fractionated into nuclei and cytoplasm, and the RNA from each fraction was extracted and subjected to S1 analysis using the probe for M1 and M2 mRNAs described in the Materials and methods. $(c)$ Cos cells were transfected with the PB1, HA, or NP gene in the absence of NS1 protein [cotransfection with NS3ss $(\mathrm{dm})$ plasmid] or presence of NS1 protein (cotransfection with NS3ss plasmid). Cells were fractionated into nuclei and cytoplasm, and the RNA from each fraction was assayed by S1 nuclease protection analysis using the probes for PB1, HA, or NP mRNA described in Materials and methods. 
a

Figure 6. The NS1 protein-mediated inhibition of transport required sequences in NS2 mRNA. (a) 293 cells were transfected with either the PB1 or the PB1-NS2 chimeric construct in the pres ence (cotransfection with NS3ss plasmid) or absence [cotransfection with NS3ss(dm) plasmid] of the NSl protein. In the first four lanes, the ratio of NS3ss to PBI plasmid and the ratio of the NS3ss $(\mathrm{dm})$ to PB1-NS2 plasmid was $2: 1$; a ratio of $3: 1$ yielded the same result. Different amounts of the NS3ss plasmid were cotransfected with the plasmid encoding the PBI-NS2 mRNA chimera. The numbers above the last four lanes indicate the ratio of the NS3ss/PB 1NS2 plasmid used for transfection. At $48 \mathrm{hr}$ posttransfection, cells were fractionated into nuclei and the cytoplasm, and extracted RNA was subjected to $\mathrm{S} 1$ nuclease protection assay using the probe depicted in $b$. The relative amount of $\mathrm{PB} 1$ mRNA and of the PB1-NS2 mRNA chimera in the nucleus and cytoplasm of each sample was determined by densitometry. The percentage of these mRNAs that were in the cytoplasm is indicated under the appropriate lanes.

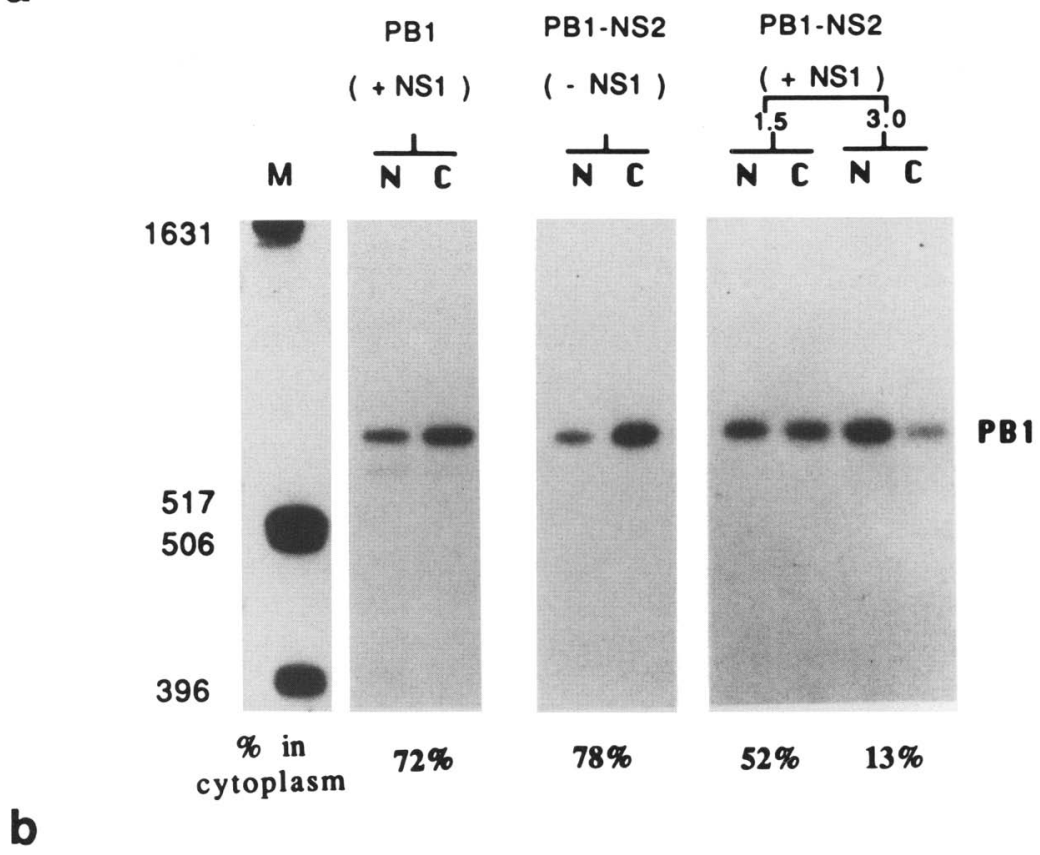

port of unspliced M1 mRNA. This suggests that the efficient nucleocytoplasmic transport of unspliced NS1 and Ml mRNAs in influenza virus-infected cells may not require the action of a Rev-like virus-specific protein. An alternative possibility is that there is a competition between transport and spliceosome formation for each species of pre-mRNA and that, consequently, a change in the overall rate of transport of all nuclear $\mathrm{mR}$ NAs and pre-mRNAs will lead to a change in the efficiency of transport of a given pre-mRNA, like the NS1 or M1 mRNA. In adenovirus-infected cells, the transport of virus-specific mRNAs and heterologous mRNAs encoded in an adenovirus vector may be significantly slower than the transport of all mRNAs in uninfected cells (Berkner and Sharp 1984, 1985; Mansour et al. 1985;
Alonso-Caplen et al. 1988), thereby explaining the lack of transport of NSI mRNA that we observed when NS1 mRNA was expressed with an adenovirus vector (Alonso-Caplen and Krug 1991). In cells in which NS1 mRNA or M1 mRNA was expressed with a transient transfection vector, nucleocy toplasmic transport may be slightly more rapid, as a small amount $(\sim 10-20 \%)$ of unspliced NS1 and M1 mRNAs was exported from the nucleus and translated (this study). Finally, in influenza virus-infected cells the transport of all viral mRNAs may be quite rapid (Herz et al. 1981; Shapiro et al. 1987), thereby enabling unspliced NS1 and M1 mRNAs to be transported efficiently without the intervention of a Rev-like protein. Host mRNAs and their precursors would not be subjected to this rapid transport because
Figure 7. Proposed post-transcriptional control of the amount of the NS2 protein in influenza virus-infected cells. (1) Cis-acting suppression of the rate of splicing of NS1 mRNA; (2) enhanced transport of NS1 mRNA; (3) NSl protein-mediated down-regulation of NS2 mRNA export.

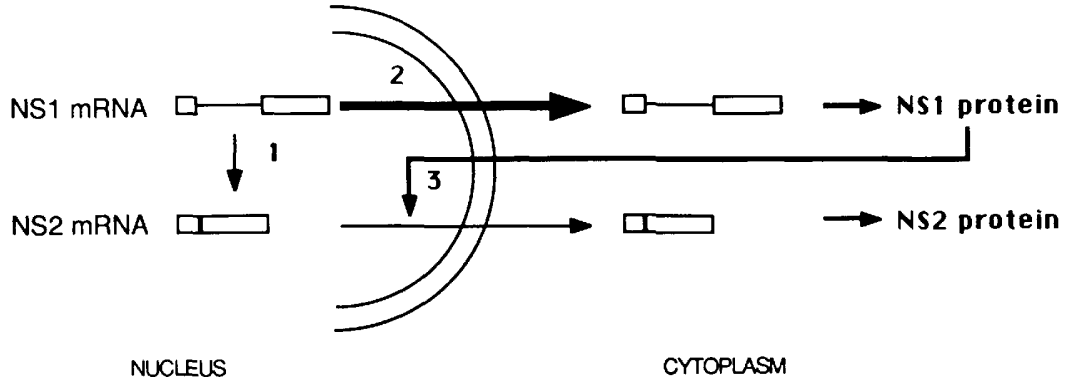

NUCLEUS
CYTOPLASM 
they are degraded in the nucleus, presumably as a result of cleavage of their $5^{\prime}$ ends by the virus-encoded capdependent endonuclease (Katze and Krug 1984). Clearly, it will be important to determine what causes the increased rate of transport of all viral mRNAs in influenza virus-infected cells.

In summary, 20 years after its discovery, we have identified at least one function of the NS1 protein. Surprisingly, it down-regulates the nuclear export of the viral spliced NS2 mRNA and its unspliced precursor, NS1 mRNA.

\section{Materials and methods}

Construction of plasmids

Oligonucleotide-directed mutagenesis with a bacteriophage M13 mutagenesis system (Boehringer Mannheim Biochemicals) was used to introduce point mutations into the NS1 or Ml gene.

The mutations were confirmed by dideoxynucleotide sequencing. The various mutations are described in Figures 1, 3, and 5. All wild-type and mutant genes were inserted into the pBC12 transfection vector (obtained from B. Cullen), which placed the genes under the control of the CMV immediate early promoter. Vector $\mathrm{pBC12/CMV/IL-2} \mathrm{was} \mathrm{digested} \mathrm{with} \mathrm{HindIII}$ and $S m a$ I to remove the interleukin (IL-2) gene. The resulting ends of the plasmid were blunt-ended using the Klenow fragment. All wild-type or mutant NS1, M1, PB1, HA, and NP genes, and the $\beta$-globin minigene (Perkins et al. 1986), with the exception of the NS3ss(dm) DNA (see Fig. 3), were inserted into the vector by blunt-end ligation. For the insertion of the NS3ss (dm) DNA, a BamHI linker was added to the ends of the plasmid (plasmid pBC12B). The NS3ss(dm) DNA, which contains $B a m H I$ ends, was inserted by sticky-end ligation into $\mathrm{pBC12B}$. Wild-type NS1, NS2, and M1 cDNAs from influenza virus A/Udorn/72 were obtained from $\mathrm{R}$. Lamb. The PBl, HA, and NP genes from influenza virus $A / P R / 8 / 34$ were obtained from P. Palese.

\section{Cell culture and transfection}

COS cells were maintained in Dulbecco's modified Eagle medium (DMEM) containing $10 \%$ fetal calf serum and were transfected with $1 \mu \mathrm{g} / \mathrm{ml}$ of plasmid DNA using DEAE-dextran and chloroquine (Cullen 1987). 293 cells were also maintained in DME containing $10 \%$ fetal calf serum and were transfected with $5-20 \mu \mathrm{g} / \mathrm{ml}$ of plasmid DNA, as indicated in the figure legends, by the calcium phosphate method (Davis et al. 1986).

\section{RNA extraction and analysis}

Transfected COS cell cultures were harvested from 48 to $72 \mathrm{hr}$ post-transfection, whereas transfected 293 cells were harvested from 36 to $48 \mathrm{hr}$ post-transfection. The cells were fractionated into nuclei and cytoplasm, as described previously (Greenberg and Ziff 1984). The fractionation was monitored by phase-contrast microscopy of the nuclear fraction and by agarose gel analysis to determine the presence of rRNA markers characteristic of the nucleus (45S) and of the cytoplasm (18S). In addition, in one experiment (Fig. 3), the fractionation was monitored by cotransfecting with a $\beta$-globin minigene and determining the nuclear/cytoplasmic distribution of unspliced and spliced $\beta$-globin mRNAs. RNA was extracted using the guanidinium isothiocyanate (Chomcynski and Sacchi 1987) method. The amount of RNA in the cytoplasm and nucleus was determined both by absorbance at $260 \mathrm{~nm}$ and by quantitating the ethidium-stained agarose gel analysis of the cytoplasmic and nuclear RNAs. Reproducible recoveries of cytoplasmic and nuclear RNAs were obtained. Cell-equivalent amounts of nuclear $(0.5$ $\mu \mathrm{g}$ ) and cytoplasmic RNAs $(5 \mu \mathrm{g})$ were assayed by S1 nuclease protection using $5^{\prime}$ end-labeled single-stranded DNA probes (Davis et al. 1986). Several different probes were used to assay NS1 and NS2 mRNAs. For the experiment described in Figure 1, the probe for NS1 and NS2 mRNAs (see Fig. 1b) was obtained by ligating an NcoI-EcoRI fragment derived from recombinant pBC 12 containing wild-type or mutant NS1 DNA to the SmaIEcoRI large fragment of M13mp9. A 29-mer oligonucleotide complementary to $\mathrm{pBCl} 2$ sequences was kinased at the $5^{\prime}$ end with $\left[\gamma^{32} \mathrm{P}\right] \mathrm{ATP}$ and was annealed to single-stranded DNA from the M13mp9 containing the NS1 DNA sequences. After primer extension using the Klenow fragment followed by AvaI digestion, the probe was purified on an alkaline-denaturing agarose gel. For the experiment described in Figure 3, the probe for NS1 and NS2 mRNAs was obtained by using a 30-mer oligonucleotide complementary to the NS3ss or NS3ss(dm) sequence, 200 nucleotides downstream from the $3^{\prime}$-splice site (see Fig. 1b). After labeling the oligonucleotide at its $5^{\prime}$ end with $\left[\gamma^{-32} \mathrm{P}\right] \mathrm{ATP}$, it was annealed to single-stranded DNA from M13mp9 containing NS3ss or NS3ss $(\mathrm{dm})$ DNAs. This was followed by primer extension using the Klenow fragment, AvaI digestion, and purification. This probe not only protected NS2 mRNA from the NS2 cDNA but also NS1 mRNA transcribed from the cotransfecting plasmids, NS3ss $(\mathrm{dm})$ and NS3ss.

The S1 assay probe used to detect M1 and M2 mRNAs was generated as follows. The mRNA $_{3} 5^{\prime}$ 'ss mutant was subcloned into the $\mathrm{pBC} 12$ transfection vector. A Sst $-A c c \mathrm{I}$ restriction fragment, containing the $\mathrm{pBCl} 2 \mathrm{CMV}$ leader, Ml 5' exon, and some Ml intron sequence was subcloned into SstI-Accl. Singlestranded DNA prepared from this recombinant M13 construct was annealed to two synthetic oligonucleotides, one complementary to the FokI site of $\mathrm{pBCl} 2$ and one complementary to the Aval site of M13mp19. The partially duplexed DNA was then digested with $A v a \mathrm{I}$ and FokI. The single-stranded FokI$A v a \mathrm{I}$ restriction fragment generated was end-labeled at the FokI end by filling in with $\left[\alpha^{-32} \mathrm{P}\right] \mathrm{dGTP}$ and using the Klenow fragment. To detect PB1 mRNA or the PB1-NS2 chimeric mRNA (see Fig. 6b), a 23-mer oligonucleotide complementary to $\mathrm{PB} 1$ sequences was kinased at the $5^{\prime}$ end with $\left[\gamma^{-32}\right.$ P $\mid$ ATP and was annealed to M $13 \mathrm{mp} 9$ containing PB1 DNA. After primer extension using the Klenow fragment, the probe was digested with Aval and purified. A similar strategy was used to make probes to detect HA, NP, and globin mRNAs except that the primer oligonucleotides, which were complementary to HA, NP, or globin sequences, were annealed to $\mathrm{M} 13 \mathrm{mp} 9$ containing $\mathrm{HA}$, NP, or globin DNA, respectively.

\section{Determination of NS1 and NS2 protein levels}

At $72 \mathrm{hr}$ post-transfection, COS cells were labeled for $6 \mathrm{hr}$ with $200 \mu \mathrm{Ci} / \mathrm{ml}$ of $\left[{ }^{35} \mathrm{~S} \mid\right.$ methionine in media depleted of $80 \%$ of its methionine. Cells were lysed as described previously (AlonsoCaplen et al. 1988), and NS1 and NS2 proteins were immunoprecipitated using monospecific antibodies obtained from $\mathbf{M}$. Krystal and P. Palese (Young et al. 1983; Greenspan et al. 1985). Proteins were analyzed on $20 \%$ SDS-polyacrylamide gels.

\section{Acknowledgments}

The initial phase of this work was carried out at Memorial Sloan-Kettering Cancer Center. This investigation was sup- 
ported by a National Institutes of Health (NIH) postdoctoral fellowship to M.E.N. (1F32AI08220-01) and an NIH grant (AI 1772, merit award) to R.M.K. We thank Helen F. Pirrello for typing this manuscript.

The publication costs of this article were defrayed in part by payment of page charges. This article must therefore be hereby marked "advertisement" in accordance with 18 USC section 1734 solely to indicate this fact.

\section{References}

Alonso-Caplen, F.V. and R.M. Krug. 1991. Regulation of the extent of splicing of influenza virus NS1 mRNA: Roles of the rates of splicing and of the nucleocytoplasmic transport of NSl mRNA. Mol. Cell Biol. 11: 1092-1098.

Alonso-Caplen, F.V., M.G. Katze, and R.M. Krug. 1988. Efficient transcription, not translation, is dependent on adenovirus tripartite leader sequences at late times of infection. I. Virol. 62: 1606-1616.

Agris, C.H., M.E. Nemeroff, and R.M. Krug. 1989. A block in mammalian splicing occurring after formation of large complexes containing U1, U2, U4, U5 and U6 small nuclear ribonucleoproteins. Mol. Cell. Biol. 9: 259-267.

Berkner, K.L. and P.A. Sharp. 1984. Expression of dihydrofolate reductase and of the adjacent $\mathrm{E} 1 \mathrm{~b}$ region in an Ad5-dihydrofolate reductase recombinant virus. Nucleic Acids Res. 12: 1925-1941.

-1985. Effect of the tripartite leader on synthesis of a non-viral protein in an adenovirus 5 recombinant. Nucleic Acids Res. 13: 841-857.

Bohnlein, S., F.P. Pirker, L. Hofer, K. Zimmermann, H. Bachmayer, E. Bohnlein, and J. Hauber. 1991. Transdominant repressors for human $\mathrm{T}$-cell leukemia virus type $1 \mathrm{Rex}$ and human immunodeficiency virus type $1 \mathrm{Rev}$ function. $/$. Virol. 65: 81-88.

Briedis, D.J., G. Conti, E.A. Munn, and B.W.J. Mahy. 1981. Migration of influenza virus-specific polypeptides from cytoplasm to nucleus of infected cells. Virology 111: 154-164.

Chang, D.D. and P.A. Sharp. 1989. Regulation by HIV Rev depends upon recognition of splice sites. Cell 59: 789-795.

Chomcynski, P. and N. Sacchi. 1987. Single-step method of RKA isolation by acid guanidinium thiocyanate-phenolchloroform extraction. Anal. Biochem. 162: 156-159.

Compans, R.W. 1973. Influenza virus proteins. II. Association with components of the cytoplasm. Virology 51: 56-70.

Company, M., J. Arenas, and J. Abelson. 1990. Requirement of the RNA helicase-like protein PRP22 for release of messenger RNA from spliceosomes. Nature 349: 487-493.

Cullen, B.R. 1987. Use of eukaryotic expression technology in the functional analysis of cloned genes. Methods Enzymol. 152: $684-703$.

Daly, T.J., K.S. Cook, G.S. Gray, T.E. Maione, and J.R. Rusche. 1989. Specific binding of HIV-1 recombinant Rev protein to the Rev-responsive element in vitro. Nature 342: 816-819.

Davis, L.G., M.D. Dibner, and J.F. Battey. 1986. Methods in molecular biology. Elsevier Science Publishing, New York.

Desselberger, U., V.R. Racaniello, J.J. Zazra, and P. Palese. 1980. The $3^{\prime}$ and 5 '-end terminal sequences of influenza $A, B$, and $C$ virus RNA segments are highly conserved and show partial inverted complementarity. Gene 8: 315-328.

Greenberg, M.E. and E.B. Ziff. 1984. Stimulation of 3T3 cells induces transcription of the c-fos proto-oncogene. Nature 311: 433-438.

Greenspan, D., P. Palese, and M. Krystal. 1988. Two nuclear location signals in the influenza virus NSI nonstructural protein. I. Virol. 54: 833-843.
Greenspan, D., M. Krystal, S. Nakada, H. Arnheiter, D.S. Lyles, and P. Palese. 1985. Expression of influenza virus NS2 nonstructural protein in bacteria and localization of NS2 in infected eucaryotic cells. J. Virol. 54: 833-843.

Hadzopoulou-Cladaras, M., B.K. Felber, C. Cladaras, A. Athanassopoulos, A. Tse, and G.N. Pavlakis. 1989. The rev (trs/ art) protein of human immunodeficiency virus type 1 affects viral mRNA and protein expression via a cis-acting sequence in the env region. I. Virol. 63: 1265-1274.

Hanly, S.M., L.T. Rimsky, M.H. Malim, J.H. Kim, J. Hauber, M. Duc Dudon, S.-Y. Le, J.V. Maizel, B.R. Cullen, and W.C. Greene. 1989. Comparative analysis of the HTLV-1 Rex and HIV-1 Rev trans-regulatory proteins and their RNA response elements. Genes \& Dev. 3: 1534-1544.

Hay, A.J., B. Lomnicizi, A.R. Bellamy, and J.J. Skehel. 1977. Transcription of the influenza virus genome. Virology 83: 337-355.

Heaphy, S., C. Dingwall, I. Ernberg, M.J. Gait, S.M. Green, J. Karn, A.D. Lowe, M. Singh, and M.A. Skinner. 1990. HIV-1 regulator of virion expression (Rev) protein binds to an RNA stem-loop structure located within the Rev response element region. Cell 60: 685-693.

Herz, C., E. Stavnezer, R.M. Krug, and T. Gurney, Jr. 1981. Influenza virus, an RNA virus, synthesizes its messenger RKA in the nucleus of infected cells. Cell 26: 391-400.

Huang, T.-S., P. Palese, and M. Krystal. 1990. Determination of influenza virus proteins required for genome replication. $I$. Virol. 64: 5669-5673.

Inglis, S.C. and C.M. Brown. 1981. Spliced and unspliced RNAs encoded by virion RNA segment 7 of influenza virus. $\mathrm{Nu}$ cleic Acids Res. 9: 2727-2740.

Inglis, S.C., T. Barrett, C.N. Brown, and J.W. Almond. 1979. The smallest genome RNA segment of influenza virus contains two genes that may overlap. Proc. Natl. Acad. Sci. 76: 37903794.

Katze, M.G. and R.M. Krug. 1984. Metabolism and expression of RNA polymerase II transcripts in influenza virus-infected cells. Mol. Cell Biol. 4: 2198-2206.

Kim, J.H., P.A. Kaufman, S.M. Hanly, L.T. Rimsky, and W.C. Greene. 1991. Rex transregulation of human T-cell leukemia virus type II gene expression. I. Virol. 65: 405-414.

Koennecke, I., C.B. Boschek, and C. Scholtissek. 1981. Isolation and properties of a temperature-sensitive mutant (ts412) of the influenza A virus recombinant with a ts lesion in the gene coding for the nonstructural protein. Virology 110: 1625.

Lamb, R.A. and P.W. Choppin. 1979. Segment 8 of the influenza virus genome is unique in coding for two polypeptides. Proc. Natl. Acad. Sci. 76; 4908-4912.

Lamb, R.A. and C.-J. Lai. 1980. Sequences of interrupted and uninterrupted mRNAs and cloned DNA coding for the two overlapping nonstructural proteins of influenza virus. Cell 21: $475-485$.

- 1982. Spliced and unspliced messenger RNAs synthesized from cloned influenza virus M DNA in an SV40 vector: Expression of the influenza virus membrane protein (M1). Virology 123: 237-256.

Lamb, R.A., P.W. Choppin, R.M. Channock, and C.-J. Lai. 1980. Mapping of two overlapping genes for polypeptides NSl and NS2 on RNA segment 8 of influenza virus genome. Proc. Natl. Acad. Sci. 78: 1857-1861.

Lamb, R.A., C.J. Lai, and P.W. Choppin. 1981. Sequences of mRNAs derived from genome RNA segment 7 of influenza virus: Colinear and interrupted mRNAs code for overlapping proteins. Proc. Natl. Acad. Sci. 78: 4170-4174.

Lazarowitz, S.G., R.W. Compans, and P.W. Choppin. 1971. In- 
fluenza virus structural and nonstructural proteins in infected cells and their plasma membranes. Virology 46: 830843.

Luytjes, W., M. Krystal, M. Enami, J.D. Parvin, and P. Palese. 1989. Amplification, expression and packaging of a foreign gene by influenza virus. Cell 59: 1107-1113.

Malim, M.H., S. Bohnlein, J. Hauber, and B.R. Cullen. 1989a. Functional dissection of the HIV-1 Rev trans-activator-derivation of a trans-dominant repressor of Rev function. Cell 58: $205-214$.

Malim, M.H., J. Hauber, S.-Y. Le, J.V. Maizel, and B.R. Cullen. 1989 b. The HIV-l rev trans-activator acts through a structural target sequence to activate nuclear export of unspliced viral mRNA. Nature 338: 254-257.

Mansour, S.L., T. Grodzicker, and R. Tjian. 1985. An adenovirus vector system used to express polyoma virus tumor antigens. Proc. Natl. Acad. Sci. 82: 1359-1363.

Nemeroff, M.E., U. Utans, A. Krämer, and R.M. Krug. 1992. Identification of cis-acting intron and exon regions in influenza virus NS1 mRNA that inhibit splicing and cause the formation of aberrantly sedimenting pre-splicing complexes. Mol. Cell. Biol. 12 (in press).

Odagiri, T. and K. Tobita. 1990. Mutation in NS2, a nonstructural protein of influenza A virus, extragenically causes aberrant replication and expression of the PA gene and leads to generation of defective interfering particles. Proc. Natl. Acad. Sci. 87: 5988-5992.

Perkins, K.K., H.M. Furneaux, and J. Hurwitz. 1986. RNA splicing products formed with isolated fractions from HeLa cells are also associated with fast-sedimenting complexes. Proc. Natl. Acad. Sci. 83: 887-891.

Plotch, S.J. and R.M. Krug. 1986. In vitro splicing of influenza viral NS1 mRNA and NS1- $\beta$-globin chimeras: Possible mechanisms for the control of viral mRNA splicing. Proc. Natl. Acad. Sci. 83: 5444-5448.

Robertson, J.S. 1979. 5' and 3' terminal nucleotide sequences of the RNA genome segments of influenza virus. Nucleic Acids Res. 6: 3745-3757.

Shapiro, G.I. and R.M. Krug. 1988. Influenza virus RNA replication in vitro: Synthesis of viral template RNAs and virion RNAs in the absence of an added primer. I. Virol. 62: 22852290.

Shapiro, G.I., T. Gurney, Ir., and R.M. Krug. 1987. Influenza gene expression: Control mechanisms at early and late times of infection and nuclear-cytoplasmic transport of virus-specific RNAs. /. Virol. 61: 764-773.

Shimizu, K., M.G. Mullinix, R.M. Channock, and B.R. Murphy. 1982. Temperature-sensitive mutants of influenza A/Udorn/ 72 (H3N2) virus. I. Isolation of temperature-sensitive mutants some of which exhibit host-dependent temperature sensitivity. Virology 117: 38-44.

Skehel, J.J. and A.J. Hay. 1978. Nucleotide sequences of the 5 '-termini of influenza virus RNAs and their transcripts. Nucleic Acids Res. 5: 1207-1219.

Skorko, R., D.F. Summers, and J.M. Galarza. 1991. Influenza A virus in vitro transcription: Roles of NSI and NP proteins in regulating RNA synthesis. Virology 180: 668-677.

Smith, G.L. and A.J. Hay, 1982. Replication of the influenza virus genome. Virology 118: 96-108.

Wolstenholme, A.J., T. Barrett, S.T. Nichol, and B.W.J. Mahy. 1980. Influenza virus-specific RNA and protein syntheses in cells infected with temperature-senstive mutants defective in the genome segment encoding nonstructural proteins. $J$. Virol. 35: 1-7.

Yoshida, T., M.W. Shaw, J.F. Young. and R.W. Compans. 1981. Characterization of the RNA associated with influenza A cytoplasmic inclusions and the interaction of NS1 protein with RNA. Virology 110: 87-97.

Young, J.F., U. Desselberger, P. Palese, B. Ferguson, A.R. Shatzman, and M. Rosenberg. 1983. Efficient expression of influenza virus NS1 nonstructural proteins in E. coli. Proc. Natl. Acad. Sci. 80: 6105-6109.

Zapp, M.L. and M.R. Green. 1989. Sequence-specific RNA binding by the HIV-1 Rev protein. Nature 342: 714-716. 


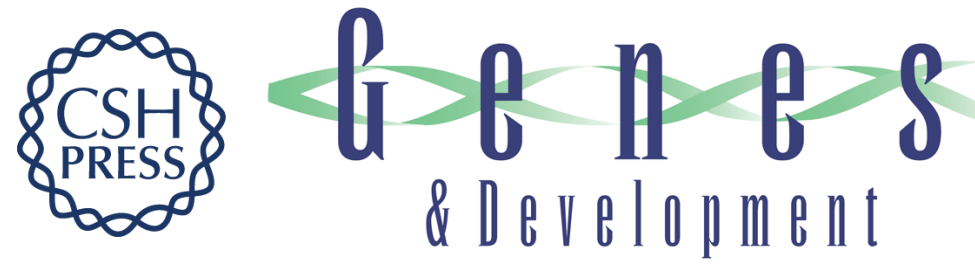

\section{Nucleocytoplasmic transport: the influenza virus NS1 protein regulates the transport of spliced NS2 mRNA and its precursor NS1 mRNA.}

F V Alonso-Caplen, M E Nemeroff, Y Qiu, et al.

Genes Dev. 1992, 6:

Access the most recent version at doi:10.1101/gad.6.2.255

References This article cites 52 articles, 21 of which can be accessed free at: http://genesdev.cshlp.org/content/6/2/255.full.html\#ref-list-1

License

Email Alerting Service

Receive free email alerts when new articles cite this article - sign up in the box at the top right corner of the article or click here.

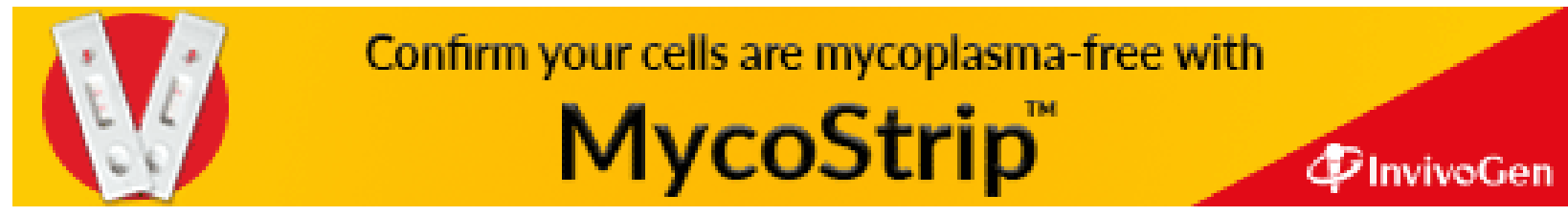

